\title{
NOTES
}

\section{Transfer of Methanolobus siciliae to the Genus Methanosarcina, Naming It Methanosarcina siciliae, and Emendation of the Genus Methanosarcina}

\author{
SHUISONG NI, ${ }^{1}$ CARL R. WOESE, ${ }^{2}$ HENRY C. ALDRICH,${ }^{3}$ AND DAVID R. BOONE ${ }^{1,4 *}$ \\ Department of Chemistry, Biochemistry and Molecular Biology ${ }^{1}$ and Department of Environmental Science and \\ Engineering, ${ }^{4}$ Oregon Graduate Institute of Science \& Technology, Portland, Oregon 97291-1000; Department \\ of Microbiology, University of Illinois, Urbana, Illinois $61801^{2}$; and Department of Microbiology \\ and Cell Science, University of Florida, Gainesville, Florida $32611^{3}$
}

\begin{abstract}
A sequence analysis of the 16S rRNA of Methanolobus siciliae $\mathrm{T} 4 / \mathrm{M}^{\mathrm{T}}$ ( $\mathrm{T}=$ type strain) showed that this strain is closely related to members of the genus Methanosarcina, especially Methanosarcina acetivorans $\mathrm{C}^{\mathrm{A}} \mathrm{A}^{\mathrm{T}}$. Methanolobus siciliae $\mathrm{T} 4 / \mathrm{M}^{\mathrm{T}}$ and $\mathrm{H} 1350$ were morphologically more similar to members of the genus Methanosarcina than to members of the genus Methanolobus in that they both formed massive cell aggregates with pseudosarcinae. Thus, we propose that Methanolobus siciliae should be transferred to the genus Methanosarcina as Methanosarcina siciliae.
\end{abstract}

Strain T4/M, the type strain of Methanolobus siciliae, was isolated from marine sediment, briefly characterized, and named (18). Later, a more complete characterization of this strain and reference strain HI350 (14) revealed physiological characteristics that supported placement of this species in the genus Methanolobus. However, in this paper we present $16 \mathrm{~S}$ rRNA sequence data for Methanolobus siciliae $\mathrm{T} 4 / \mathrm{M}^{\mathrm{T}}(\mathrm{T}=$ type strain) which indicate that this species should be transferred to the genus Methanosarcina. Strain T4/M ${ }^{\mathrm{T}}$ (= OCM $156^{\mathrm{T}}$ ) was grown in MSH medium (14) by using modifications of the Hungate techniques (5). Cells were grown on $20 \mathrm{mM}$ trimethylamine in a 2-liter bottle containing $1,200 \mathrm{ml}$ of medium and were collected by centrifugation at $10,000 \times g$. The $16 \mathrm{~S}$ rRNA was sequenced by the reverse transcriptase method. The sequence was then aligned by using a sequence editor with a representative collection of archaeal 16S rRNA sequences $(2,20)$. Because of the degree of similarity among these sequences, the alignment procedure was a straightforward manual one. Previously aligned close relatives of the new sequence, established secondary structural constraints, and sequence conservation patterns were used to guide the process (20). Corrected pairwise distances (expressed as estimated number of changes per 100 nucleotides) were computed from percentages of similarity by using the Jukes-Cantor correction (6) as modified by Olsen (19). A dendrogram (Fig. 1) was constructed from the evolutionary distance matrix by using the algorithm of De Soete (4). Figure 1 shows that strain $T 4 / M^{T}$ is phylogenetically more closely related to the genus Methanosarcina than to the genus Methanolobus. Therefore, we propose that Methanolobus siciliae should be transferred to the genus Methanosarcina and named Methanosarcina siciliae comb. nov.

\footnotetext{
* Corresponding author. Mailing address: Department of Environmental Science and Engineering, Oregon Graduate Institute, P.O. Box 91000, Portland, OR 97291-1000. Phone: (503) 690-1146. Fax: (503) 690-1273. Electronic mail address: boone@ese.ogi.edu.
}

As previously defined, the genera Methanolobus (18) and Methanosarcina (12) differ in substrate range, morphology, and halophily (2). All Methanolobus species grow exclusively on simple methylated compounds, such as methanol, methylamines, and sometimes methyl sulfides (dimethylsulfide and methane thiol) $(7,14-16)$. In contrast, all species currently assigned to the genus Methanosarcina grow on $\mathrm{H}_{2}-\mathrm{CO}_{2}$ or acetate in addition to methanol and methylamines $(2,10)$, but no strain currently assigned to the genus Methanosarcina has been reported to grow on dimethylsulfide or methane thiol (15). Methanosarcina siciliae $\mathrm{T} 4 / \mathrm{M}^{\mathrm{T}}$ and HI350 can grow on dimethylsulfide and methane thiol in addition to methanol and trimethylamine, but Methanosarcina mazeii LYC and C 16 cannot $(14,15)$. We found that Methanosarcina acetivorans $\mathrm{C} 2 \mathrm{~A}^{\mathrm{T}}$, which had not been tested previously for growth on dimethylsulfide, was also able to catabolize dimethylsulfide, as shown in the experiment described below. A culture of Methanosarcina acetivorans $\mathrm{C} 2 \mathrm{~A}^{\mathrm{T}}\left(=\mathrm{OCM} 95^{\mathrm{T}}\right)$ was obtained from the Oregon Collection of Methanogens, Portland, Oreg., grown in MS medium (1) supplemented with $50 \mathrm{mM}$ methanol, and inoculated (inoculum volume, $2.5 \%$ ) into medium containing $4.5 \mathrm{mM}$ dimethylsulfide, as well as three control media containing the following growth substrates: (i) none; (ii) 25 $\mathrm{mM}$ methanol; and (iii) $25 \mathrm{mM}$ methanol plus $4.5 \mathrm{mM}$ dimethylsulfide. We used large bottles (volume, $600 \mathrm{ml}$ ) containing $300 \mathrm{ml}$ of media so dimethylsulfide could be added directly as a liquid and to minimize the fraction of dimethylsulfide lost by diffusion into the stoppers. Within days, cultures containing methanol produced approximately the amount of methane stoichiometrically expected from methanol. After a lag of about 1 week, the bottles containing dimethylsulfide began to produce methane, and this continued until the amount of methane produced was approximately equal to the amount expected stoichiometrically from the dimethylsulfide. Methane production was accompanied by an obvious increase in the turbidity of the medium and an increase in cells visible by epifluorescence microscopy. This finding indicates that Methanosarcina acetivorans and Methanosarcina siciliae are the 


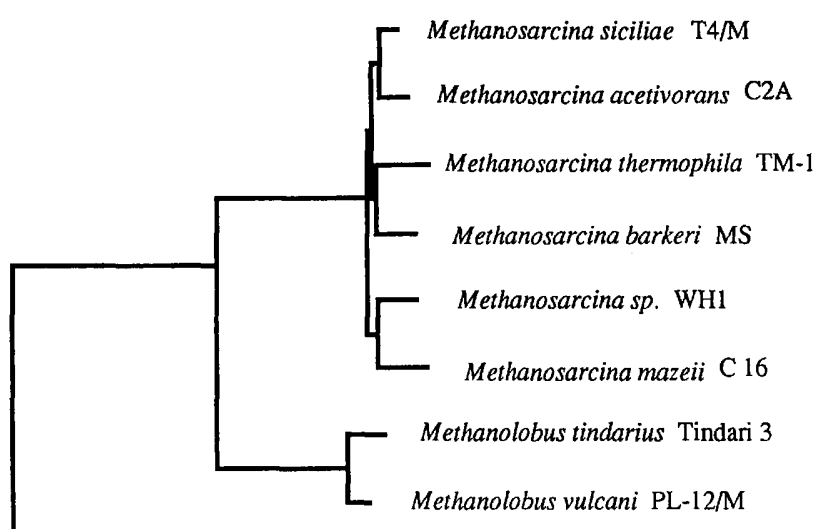

Methanoplanus limicola M3

$10 \%$

FIG. 1. Phylogenetic relationships of Methanolobus and Methanosarcina species, based on 16S rRNA sequences.

only dimethylsulfide-degrading species of the genus Methanosarcina.

Methanolobus cells also differ morphologically from Methanosarcina cells. Methanolobus cells are irregular cocci and occur either singly or in small aggregates in all growth stages. In contrast, the cells of many Methanosarcina strains undergo morphological changes at different growth phases $(3,11,13$, 17). In young Methanosarcina cultures, individual coccoid cells form aggregates having pseudosarcinal shapes, which then become "cysts" of various sizes; the cysts have a common external wall composed of heteropolysaccharide. These large cell aggregates and cysts may be disrupted either physically or enzymatically. Physical disruption yields myriads of smaller irregular elements, whereas enzymatic action by disaggregatase can turn the cysts or aggregates into single cells, thereby dispersing the rapidly settling clumps and producing turbid suspensions $(9,21)$.

We found that Methanosarcina siciliae $\mathrm{T} 4 / \mathrm{M}^{\mathrm{T}}$ and $\mathrm{HI} 350$ (= OCM 210) cells often grew in large aggregates. This characteristic is more typical of members of the genus Methanosarcina than of members of the genus Methanolobus. During the initial characterization of these strains, we observed only irregular coccoid cells that occurred singly or in small aggregates (14). However, when the cultures were later transferred repeatedly in MSH medium containing dimethylsulfide as a catabolic substrate, the cells grew in massive clumps consisting of pseudosarcinae (Fig. 2A). Similar clumps were also observed in cultures growing on methanol or trimethylamine if relatively young cultures were transferred repeatedly during the mid-exponential growth phase. These clumps could be disrupted into smaller cell aggregates by physical shaking. Prolonged incubation after exhaustion of substrate induced spontaneous disaggregation, releasing single cells and causing the culture to become turbid. Media having $\mathrm{pH}$ values below 7 favored clump formation. Electron microscopy of thin sections, however, did not reveal a continuous wall structure surrounding the pseudosarcinae, as is often seen in Methanosarcina barkeri and Methanosarcina mazeii; instead, there was only amorphous wall material at the surfaces of single cells (Fig. 2B), reminiscent of the cell walls of Methanolobus tindarius Tindari $3^{\mathrm{T}}(8)$. Cells were not as tightly stuck together as typical Methanosarcina cells in their clumps. Both individual
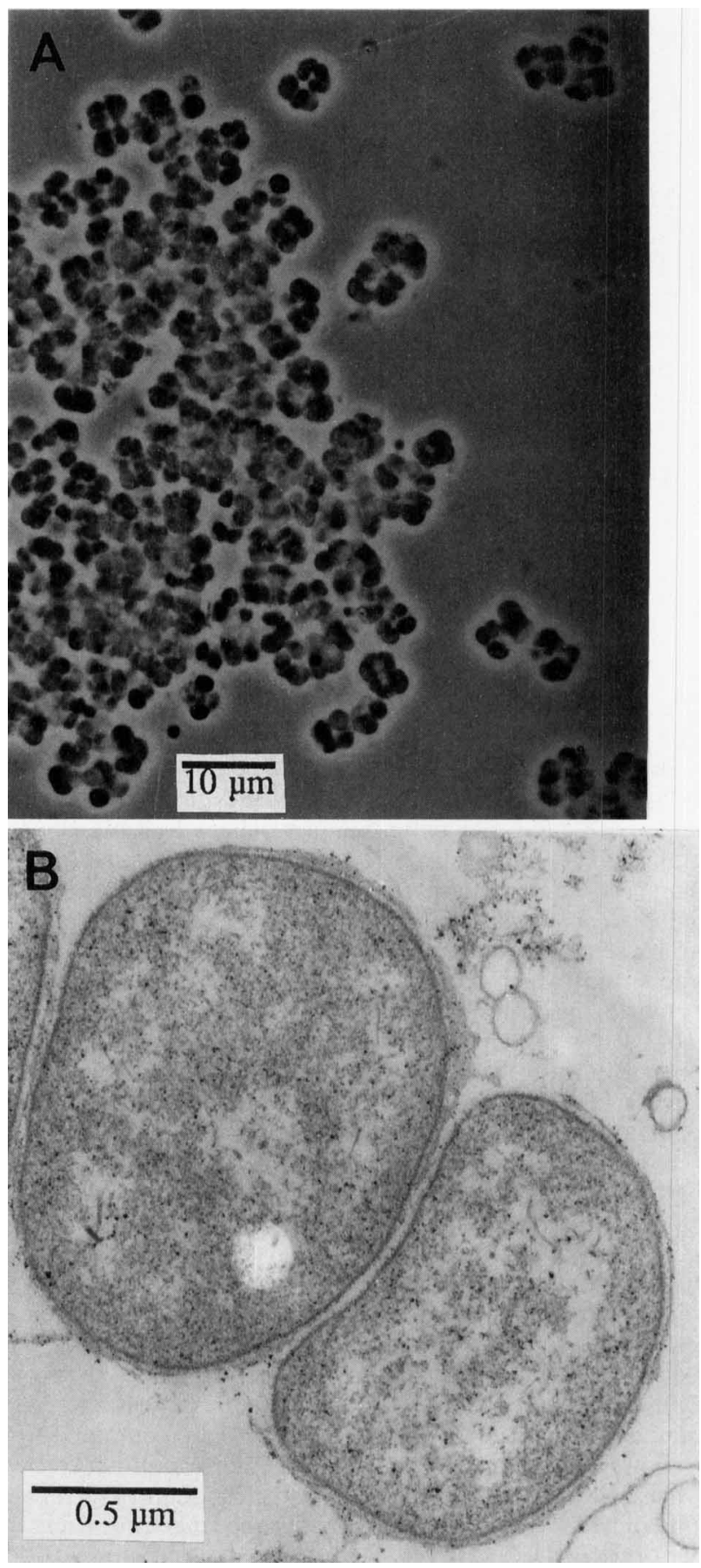

FIG. 2. (A) Phase-contrast micrograph of cell aggregates of Methanosarcina siciliae HI350. (B) Thin-section micrograph of Methanosarcina siciliae HI350. Cells for electron microscopy were fixed at room temperature for $30 \mathrm{~min}$ in $2.5 \%$ glutaraldehyde buffered to $\mathrm{pH} 7.4$ with $0.2 \mathrm{M}$ sodium cacodylate. They were then postfixed in osmium tetroxide for $30 \mathrm{~min}$ at $4^{\circ} \mathrm{C}$, dehydrated, and embedded in Spurr low-viscosity resin. Sections were poststained with uranyl acetate and lead citrate, examined, and photographed with a Zeiss model EM-10 transmission electron microscope at $60 \mathrm{kV}$. 
cells and massive cell clumps of Methanosarcina siciliae $\mathrm{T} 4 / \mathrm{M}^{\mathrm{T}}$ and HI350 lysed immediately when $2 \mathrm{~g}$ of sodium dodecyl sulfate per liter was added, and no visible cellular framework remained. In contrast, when Methanosarcina barkeri clumps or some Methanosarcina mazeii clumps are treated with dodecyl sulfate, the intact cell shapes are microscopically visible (9). This finding suggested that Methanosarcina siciliae $\mathrm{T} 4 / \mathrm{M}^{\mathrm{T}}$ and HI350 had proteinaceous cell walls similar to those of Methanosarcina acetivorans $\mathrm{C}^{2} \mathrm{~A}^{\mathrm{T}}$ and Methanosarcina mazeii $\mathrm{C} 16$ (= Methanosarcina frisia C $\left.16^{\mathrm{T}}[10]\right)$ and Gö1. Cysts, commonly known as the third morphological state of many Methanosarcina strains (12), were not observed in cultures of strain $\mathrm{T} 4 / \mathrm{M}^{\mathrm{T}}$ or HI350.

Our results showed unequivocally that strain $\mathrm{T} 4 / \mathrm{M}^{\mathrm{T}}$ is more closely related to Methanosarcina species than to Methanolobus species. Among the Methanosarcina strains compared, strain $\mathrm{T} 4 / \mathrm{M}^{\mathrm{T}}$ was most closely related to Methanosarcina acetivorans $\mathrm{C} 2 \mathrm{~A}^{\mathrm{T}}$. Methanosarcina acetivorans $\mathrm{C}^{\mathrm{A}} \mathrm{A}^{\mathrm{T}}$ differs physiologically from Methanosarcina siciliae $\mathrm{T} 4 / \mathrm{M}^{\mathrm{T}}$ and HI350. Methanosarcina acetivorans $\mathrm{C}^{2} \mathrm{~A}^{\mathrm{T}}$ can grow on acetate in addition to methanol, methylamines (17), and dimethylsulfide. This species is now considered halotolerant (10), although strains have been isolated only from marine sediments (17). Phylogenetically, Methanosarcina acetivorans and Methanosarcina siciliae are closely related; the $16 \mathrm{~S}$ rRNA sequences of their type strains exhibit $98.3 \%$ similarity. This level of difference is typical of closely related species (2) or even strains within the same species. Thus, in the absence of DNA-DNA reassociation data, we consider Methanosarcina siciliae and Methanosarcina acetivorans separate Methanosarcina species.

All previously described Methanosarcina strains are nonhalophilic and catabolize either acetate or $\mathrm{H}_{2}-\mathrm{CO}_{2}$ (or both) in addition to methanol and methylamines. With the inclusion of Methanosarcina siciliae in this genus, however, these characteristics cannot be considered diagnostic criteria for the genus Methanosarcina (12). Thus, we hereby emend the description of the genus Methanosarcina to include slightly halophilic, nonaceticlastic, obligate methylotrophs. The range of catabolic substrates for Methanosarcina species is also expanded to include dimethylsulfide and methane thiol.

We thank Yitai Liu and Priya Kadam for helpful discussions.

This work was supported by section 105 grant 14-08-001-G1636 from the U. S. Geological Survey.

\section{REFERENCES}

1. Boone, D. R., R. L. Johnson, and Y. Liu. 1989. Diffusion of the interspecies electron carriers $\mathrm{H}_{2}$ and formate in methanogenic ecosystems and its implications in the measurement of $K_{m}$ for $\mathrm{H}_{2}$ or formate uptake. Appl. Environ. Microbiol. 55:1735-1741.

2. Boone, D. R., W. B. Whitman, and P. Rouvière. 1993. Diversity and taxonomy of methanogens, p. 35-80. In J. G. Ferry (ed.), Methanogenesis. Chapman \& Hall, New York.

3. Bryant, M. P., and D. R. Boone. 1987. Emended description of strain $\mathrm{MS}^{\mathrm{T}}\left(\mathrm{DMS} 800^{\mathrm{T}}\right.$ ), the type strain of Methanosarcina barkeri. Int. J. Syst. Bacteriol. 37:169-170.

4. De Soete, G. 1983. A least squares algorithm for fitting additive trees to proximity data. Psychometrika 48:621-626.
5. Hungate, R. E. 1969. A roll tube method for cultivation of strict anaerobes. Methods Microbiol. 3B:117-132.

6. Jukes, T. H., and C. R. Cantor. 1969. Evolution of protein molecules, p. 21-132. In H. N. Munro (ed.), Mammalian protein metabolism. Academic Press, New York.

7. König, H., and K. O. Stetter. 1982. Isolation and characterization of Methanolobus tindarius sp. nov., a coccoid methanogen growing only on methanol and methylamines. Zentralbl. Bakteriol. Parasitenkd. Infektionskr. Hyg. Abt. 1 Orig. Reihe C 3:478-490.

8. König, H., and K. O. Stetter. 1986. Studies on archaebacterial S-layers. Syst. Appl. Microbiol. 7:300-309.

9. Liu, Y., D. R. Boone, R. Sleat, and R. A. Mah. 1985. Methanosarcina mazei $\mathrm{LYC}$, a new methanogenic isolate which produces a disaggregating enzyme. Appl. Environ. Microbiol. 49:608-613.

10. Maestrojuán, G. M., J. E. Boone, R. A. Mah, J. A. G. F. Menaia, M. S. Sachs, and D. R. Boone. 1992. Taxonomy and halotolerance of mesophilic Methanosarcina strains, assignment of strains to species, and synonymy of Methanosarcina mazei and Methanosarcina frisia. Int. J. Syst. Bacteriol. 42:561-567.

11. Mah, R. A. 1980. Isolation and characterization of Methanococcus mazei. Curr. Microbiol. 3:321-326.

12. Mah, R. A., and D. R. Boone. 1989. Genus I. Methanosarcina Kluyver and van Niel 1936, 400 $\mathrm{AL}$, emend. Mah and Kuhn 1984 , 266 (Nom. Cons. Opin. 63 Jud. Comm. 1986, 492), p. 2199-2205. In J. T. Staley, M. P. Bryant, N. Pfennig, and J. G. Holt (ed.), Bergey's manual of systematic bacteriology, vol. 3. The Williams \& Wilkins Co., Baltimore.

13. Mah, R. A., and D. A. Kuhn. 1984. Transfer of the type species of the genus Methanococcus to the genus Methanosarcina, naming it Methanosarcina mazei (Barker 1936) comb. nov. et emend., and conservation of the genus Methanococcus with Methanococcus vannielii as the type species. Int. J. Syst. Bacteriol. 34:263-265.

14. Ni, S., and D. R. Boone. 1991. Isolation and characterization of a dimethylsulfide-degrading methanogen, Methanolobus siciliae HI350, from an oil well, characterization of $M$. siciliae $\mathrm{T} 4 / \mathrm{M}^{\mathrm{T}}$, and emendation of $M$. siciliae. Int. J. Syst. Bacteriol. 41:410-416.

15. Ni, S., and D. R. Boone. 1993. Catabolism of dimethylsulfide and methane thiol by methylotrophic methanogens, p. 796-810. In R. S. Oremland (ed.), Biogeochemistry of global change. Chapman \& Hall, Inc., New York.

16. Oremland, R. S., R. P. Kiene, M. J. Whiticar, and D. R. Boone. 1989. Description of an estuarine methylotrophic methanogen which grows on dimethyl sulfide. Appl. Environ. Microbiol. 55: 944-1022.

17. Sowers, K. R., S. F. Baron, and J. G. Ferry. 1984. Methanosarcina acetivorans sp. nov., an acetotrophic methane-producing bacterium isolated from marine sediments. Appl. Environ. Microbiol. 47:971-978.

18. Stetter, K. O. 1989. Genus II. Methanolobus König and Stetter 1983, 439, p. 2205-2297. In J. T. Staley, M. P. Bryant, N. Pfennig, and J. G. Holt (ed.), Bergey's manual of systematic bacteriology, vol. 3. The Williams \& Wilkins Co., Baltimore.

19. Weisburg, W. G., J. G. Tully, D. L. Rose, J. P. Petzel, H. Oyaizu, D. Yang, L. Mandelco, J. Sechrest, T. G. Lawrence, J. van Etten, J. Maniloff, and C. R. Woese. 1989. A phylogenetic analysis of the mycoplasmas: basis for their classification. J. Bacteriol. 171:64556467.

20. Woese, C. R., R. Gutell, R. Gupta, and H. F. Noller. 1983. Detailed analysis of the higher-order structure of $16 \mathrm{~S}$-like ribosomal ribonucleic acids. Microbiol. Rev. 47:621-669.

21. Xun, L., R. A. Mah, and D. R. Boone. 1990. Isolation and characterization of disaggregatase from Methanosarcina mazei LYC. Appl. Environ. Microbiol. 56:3693-3698. 